\title{
JUURNAL.RU
}

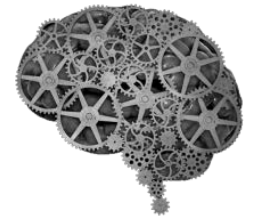

COMPANY GROUP "INTELLEKT"

\author{
Чилимова Т.А. \\ Уральский государственный экономический университет \\ Екатеринбург, Россия
}

doi: 10.18411/lj2016-5-5-15

\section{Эффективное управление государственной собственностью: образовательный аспект}

В современной системе субъектов экономики «государство - бизнес домашнее хозяйство» одно из ключевых мест занимает государство и государственная собственность. Именно в этом аспекте сегодня идет дискуссия о расширении или сужении объемов государственной собственности и влиянии этого процесса на развитие российской экономики.

Для достижения целей устойчивого экономического и социального развития необходимо не столько количественное, сколько качественное изменение госсектора, позволяющее превратить этот сектор в конкурентоспособную часть экономики. При этом нужно учитывать два фактора. Во-первых, экономика России - это не рыночная экономика развитого западного государства. И отношения собственности в России исторически развивались в других формах, чем на Западе. Поскольку развитие происходило в условиях социально-экономического кризиса и политической нестабильности, то государственная собственность объективно не смогла стать эффективным экономическим регулятором. Второй фактор заключается в том, что соотношение между государственным и частным сектором, государственной и частной собственностью может меняться на различных этапах развития экономики. Возможность изменения этого соотношения объективно обуславливается тенденциями развития, качеством экономического роста, 
изменениями структуры и значимости факторов, его определяющих.

Государственный сектор является одним из инструментов реализации экономической стратегии развития российского общества. Управляя этим сектором экономики, государство имеет возможность проводить различные виды политики: ценовую, инвестиционную, структурную; может регулировать деятельность монополий, стимулировать развитие научно-технического прогресса, поддерживать занятость, обеспечивать функционирование низкорентабельных производств, не представляющих интереса для частного бизнеса, но имеющих значение для общества в целом.

В связи с этим можно выделить четыре задачи государства-собственника, требующие первоочередного решения. Первая задача состоит в восстановлении управляемости госсектора экономики, учитывая, что на предприятиях госсектора занята достаточно большая доля рабочей силы - примерно $37 \%$ работающих. При решении этой задачи необходимо учитывать, что госсектор связан не с отдельными секторами и отраслями, а со всей экономикой в целом. Поэтому необходимо сформировать сектор экономики из предприятий жизненно важных отраслей всех форм собственности. В его состав должны входить топливно-энергетический комплекс, агропромышленный комплекс, оборонная промышленность, транспорт федерального уровня, атомная энергетика, космос, связь и ряд других сфер. Но, чтобы управляемый государством сектор стал рыночным, необходимо применять не только законодательные и административные меры управления, а также экономические методы и инструменты.

Вторая задача связана с повышением эффективности управления государственной собственностью. Для этого сегодня создается единая национальная система оценки и управления государственной собственностью. Решение этой задачи ведет к существенному сжатию огромного теневого сектора, его легализации, увеличению налогооблагаемого оборота и доходов бюджета. Одновременно расширяются возможности реального сектора 
экономики.

Третья задача заключается в поиске путей осуществления предпринимательской деятельности государства, основанных на рыночных формах сочетания государственного и частного капитала. Государство должно стать реальным партнером частного бизнеса. Например, представляя на взаимовыгодных условиях коммерческое госимущество в управление частному капиталу через механизм концессии и аренды, государство может включить в хозяйственный оборот не задействованные ранее объекты своей собственности, тем самым, создавать дополнительные рабочие места, увеличивать налоговые поступления и т.п. В результате государство получает рост капитализации своих объектов.

Особую роль в этой системе отводится государственному акционерному капиталу. Целями управления пакетами акций, находящихся в государственной собственности, являются:

1) максимизация неналоговых доходов бюджета, т.е. дивидендов;

2) обеспечение выполнения хозяйственными обществами общегосударственных функций (социальные программы, регулирование естественных монополий);

3) оптимизация управленческих затрат (сокращение количества обществ, в которых имеется доля государства, расходов, связанных с управлением);

4) реструктуризация предприятий, создание вертикально интегрированных структур;

5) стимулирование развития производства, улучшение общих финансовоэкономических показателей деятельности хозяйственных обществ и привлечение инвестиций;

6) снижение рисков при выделении инвестиционных ресурсов хозяйствующим субъектам, относящимся к негосударственным формам собственности. 
Поставленные цели невозможно реализовать в рамках действующего института представителей государства в акционерных обществах. Все представители государства в органах управления акционерными обществами - государственные служащие, большинство из которых не имеет ни образования, ни навыков в управлении государственной собственностью.

Говоря о неэффективности института государственных представителей в акционерных обществах, необходимо отметить, что нередко даже в тех акционерных обществах, в которых у государства имеется контрольный пакет акций и представители государства участвуют в общих собраниях акционеров, в заседаниях совета директоров, в решении вопроса о назначении исполнительных органов общества, положительных показателей деятельности нет, а в отдельных случаях решения представителей противоречат интересам государства.

Очевидно, что при таком подходе к исполнению обязанностей представителя государства говорить об их эффективной работе не приходится.

Реализация полномочий государства как собственника - субъекта корпоративных отношений - в органах управления акционерным обществом требует основательных знаний в области корпоративного права, умения, опираясь на имеющийся опыт, принимать точные и оперативные решения, касающиеся почти всех аспектов деятельности компании.

Можно с уверенностью утверждать, что в нынешнем виде институт представителя государства в акционерном обществе существовать не может и не должен.

Решение данной проблемы предполагает два варианта. Первым вариантом может стать крупномасштабное введение в практику управления государственными пакетами акций института доверительного управляющего.

Второй вариант - замена представителей государства (государственных чиновников) в акционерных обществах на профессиональных менеджеров, назначенных по рекомендации, и связанных с государством договорными отношениями. 
Таким образом, постановка четвертой задача логично вытекает из трех предыдущих задач - для достижения наибольшей эффективности управления государственной собственности необходим переход на профессиональный менеджмент государственной собственности. Речь должна идти о подготовке и формировании нового слоя управленческих кадров: управляющих активами госпредприятий, государственными пакетами акций в акционерных обществах, государственными объектами недвижимости и т.п.

В первую очередь это связано с современным положением дел в системе управления государственной собственностью. Одним из основных инструментом управления предприятиями смешанной формы собственности стало представительство интересов государства в акционерных обществах с государственным участием. Оно получило наибольшее распространение. Суть этого метода сводится к тому, что функцию представительства интересов государства, как одного из акционеров, выполняют работники государственного ведомства (министерства), в ведении которого находится данное предприятие, то есть представителями государства являются чиновники.

Анализ эффективности использования данного метода показывает, что такое представительство носило и продолжает носить формальный характер. Основное объяснение этого заключается в том, что государственный чиновник, не имея профессиональной подготовки, не в состоянии эффективно управлять пакетами акций, принадлежащих государству. Функции Советов директоров, где участвуют представители государства, как правило, сводятся к реализации решений, принятых на более высоком - правительственном - уровне. Таким образом, чиновник-представитель государства не несут персональной ответственности за свою деятельность, т.е. нарушается принцип фидуциарной ответственности.

В результате такой системы управления представителями государства не обеспечивается должный контроль, что продолжает приводить к размыванию доли государства в акционерном капитале при дополнительных эмиссиях, 
недополучению дивидендов в бюджет, уменьшению доли государства в ряде компаний, имеющих важное стратегическое значение для обеспечения национальной безопасности.

По оценке специалистов, в компаниях с государственным участием в 2,5 раза ниже, чем в частных, представительство независимых директоров, т. е. людей с опытом управления в крупных корпорациях, финансовых специалистов, способных реально контролировать менеджмент и обсуждать стратегии развития бизнеса, в том числе в интересах государства.

Таким образом, подготовка профессиональных менеджеров-специалистов в управлении государственной собственностью становится приоритетной задачей.

В рамках решения этой задачи необходимо выстроить уровневую систему подготовки специалистов. Причем обучение профессиональных менеджеров необходимо проводить именно с экономической точки зрения, т.е. в рамках экономических ВУЗов. Набор дисциплин для их подготовки должен включать, кроме правовых и управленческих, достаточно большие экономические и финансовые блоки.

Одним из основных условий формирования в ВУЗе эффективной системы подготовки профессиональных менеджеров по управлению государственной собственностью является наличие научной школы.

Создание и функционирование научных школ подразумевает взаимодействие связи «учитель - ученик» на следующих друг за другом этапах воспроизводства подобных кадров в ВУЗе: обучение бакалавров и магистрантов; профессиональная деятельность молодых специалистов госсектора; послевузовское профессиональное образование в аспирантуре; научная деятельность молодых ученых в ВУЗе по специальности; послевузовское профессиональное образование в докторантуре.

Начиная с уровня «молодых специалистов» и далее целесообразно установление обратной связи: «ученики» более высокой профессиональной 
квалификации могут быть научными руководителями, т.е. «учителями» на более низком уровне. Например, аспиранты, имеющие профессиональный опыт в управлении государственной собственностью, могут стать научными руководителями студентов, кандидаты и доктора наук - научными руководителями студентов и молодых ученых.

Решение этой задачи при прочих условиях позволит государству стать эффективным собственником, что, в свою очередь, обеспечит дальнейший поступательный экономический рост российской экономики в целом.

Chilimova T.

Ural state economic university,

Ekaterinburg

\section{Effective management of state property: an educational aspect}

Abstract. The paper deals with issues related to the need to improve the management of State property, and its impact on the development of the Russian economy. One of the most important aspects of the consideration of this problem is to increase the professionalism of the subjects in governance. The powers of the State as an owner requires specific knowledge in the field of corporate law, corporate governance and corporate finance. While training of professional managers must be made primarily in the framework of the economic universities. One of the main conditions of formation in high school an effective system of training professional managers for the management of State property is the presence of scientific school.

Key words: state regulation of economy, state property, professional management, scientific school 


\section{Литература:}

1. Ерохин С.3. Анализ этапов постиндустриальной трансформации // Новая экономика: монография [Текст] / под ред. Е.Ф.Авдошкина, В.С.Сизова; ВСЭИ. - М.: Магистр, 2009. - С.72-90.

2. Рынок труда, занятость и заработная плата [Электронный ресурс] - URL: http://www.pocстат.ru.

3. Стратегия национальной безопасности России до 2020 года [Электронный pecypc] - URL: http://www.scrf.gov.ru.

4. Трансформация государственной собственности в условиях смешанной экономики [Текст] /отв. ред. А.Г.Зельднер, И.Ю.Ваславская; Ин-т экономики РАН. - М: Наука, 2006. - 261 с.

5. Чайка Ю. Доклад о результатах проверки госкорпораций: [Электронный pecypc]. - Режим доступа: http://www.vedomosti.ru.

6. Чилимова Т.А. К вопросу об участии государства в системе корпоративного управления [Текс]//Управленец. - №9-10 (38). - С.18-21. 